\title{
Development of a Cloud-Point Extraction Method for Cobalt Determination in Natural Water Samples
}

\author{
Mohammad Reza Jamali, Mohammad Gholinezhad, Saiedeh Balarostaghi, \\ Reyhaneh Rahnama, and Seyed Hojjat Allah Rahimi
}

Department of Chemistry, Payame Noor Universtiy, P.O. BOX 19395-3697, Tehran, Iran

Correspondence should be addressed to Mohammad Reza Jamali; mr_jamali@ymail.com

Received 11 January 2012; Accepted 15 April 2012

Academic Editor: Juan Campora

Copyright (c) 2013 Mohammad Reza Jamali et al. This is an open access article distributed under the Creative Commons Attribution License, which permits unrestricted use, distribution, and reproduction in any medium, provided the original work is properly cited.

\begin{abstract}
A new, simple, and versatile cloud-point extraction (CPE) methodology has been developed for the separation and preconcentration of cobalt. The cobalt ions in the initial aqueous solution were complexed with 4-Benzylpiperidinedithiocarbamate, and Triton X114 was added as surfactant. Dilution of the surfactant-rich phase with acidified ethanol was performed after phase separation, and the cobalt content was measured by flame atomic absorption spectrometry. The main factors affecting $\mathrm{CPE}$ procedure, such as $\mathrm{pH}$, concentration of ligand, amount of Triton X-114, equilibrium temperature, and incubation time were investigated and optimized. Under the optimal conditions, the limit of detection (LOD) for cobalt was $0.5 \mu \mathrm{g} \mathrm{L} \mathrm{L}^{-1}$, with sensitivity enhancement factor (EF) of 67. Calibration curve was linear in the range of $2-150 \mu \mathrm{g} \mathrm{L}^{-1}$, and relative standard deviation was $3.2 \%\left(c=100 \mu \mathrm{g} \mathrm{L} \mathrm{L}^{-1} ; n=10\right)$. The proposed method was applied to the determination of trace cobalt in real water samples with satisfactory analytical results.
\end{abstract}

\section{Introduction}

Trace metals play an important role in human metabolism, and either excess or deficiency of them in the living organism can lead to biological disorder [1]. The determination of trace amounts of cobalt in natural waters is of great interest because cobalt is important for living species as complexed vitamin $B_{12}$. Vitamin $B_{12}$ is present in human and animal cells in the forms of adenosylcobalamin (III) and methylcobalamin (IV). The deficiency of cobalt in ruminants usually results in different types of anaemia. Toxicological effects of large amounts of cobalt include vasodilation, flushing, and cardiomyopathy in humans and animals. The importance of cobalt in human and ruminant nutrition has led to work on the determination of cobalt in soils, plants, feedstuffs, herbage, natural waters, and fertilizers. Investigations have been extended to the biochemistry of cobalt in animals, humans, microorganisms, and enzymes [2]. The maximum recommended concentration of cobalt in drinking water for livestock is $1.0 \mathrm{mg} \mathrm{L}^{-1}$ [3]. For drinking water for human consumption, the upper limits are even less. It is, therefore, clear that a reliable analytical method must be established to test waters and soils on a regular basis.

Several analytical techniques such as atomic absorption spectrometry (AAS), inductively coupled plasma atomic emission spectrometry (ICP-AES), and inductively coupled plasma mass spectrometry (ICP-MS) are available for the determination of trace metals with sufficient sensitivity in most applications. However, the determination of trace metal ions in natural waters is difficult due to various factors, particularly their low concentrations and matrix effects. Preconcentration and separation can solve these problems and lead to a higher confidence level and an easy determination of the trace elements by less sensitive, but more accessible instrumentation such as flame atomic absorption spectrometry (FAAS). There are many methods of preconcentration and separation such as liquid-liquid extraction (LLE) $[4,5]$, ion exchange techniques $[6,7]$, coprecipitation $[8,9]$, and sorption on various adsorbents such as activated carbon $[10,11]$, Amberlite XAD resins $[12,13]$, and other sorbents $[14,15]$. However, these methods which are typically timeconsuming and labor-intensive have multistep procedures 
prone to loss of analytes and need high volumes of samples. Therefore, simple, rapid, and efficient techniques that can be used easily are required.

Cloud-point extraction (CPE) is probably the most versatile and simple method for the preconcentration and extraction of hydrophobic species from water. The technique is based on the property of most nonionic surfactants in aqueous solutions to form micelles and become turbid when heated to a temperature known as the cloud point temperature (CPT). Above this temperature, the micellar solution separates in a surfactant rich phase of a small volume and in a diluted aqueous phase in which the surfactant concentration is close to the critical micellar concentration. The ability of micellar systems to concentrate and extract hydrophobic species from water was demonstrated some years ago [1618]. In recent years, cloud point methodology has been used for the extraction and preconcentration of metal ions after the formation of sparingly water soluble complexes [19-22]. The aim of this work is to apply cloud point extraction as a preconcentration step for flame atomic absorption spectrometric determination of cobalt in natural water samples by the use of 4-benzylpiperidinedithiocarbamate potassium salt as a complexing agent.

\section{Experimental}

2.1. Instrumentation. A PG-990 (PG instrument Ltd., UK) atomic absorption spectrometer equipped with deuterium background correction and cobalt hollow cathode lamp was used for the determination of cobalt in the surfactant-rich phase at wavelength of $240.7 \mathrm{~nm}$. The instrumental parameters were adjusted according to the manufacturer's recommendations. Cloud point preconcentration experiments were performed using a Memmert thermostated bath (Model WNB-14, Germany), maintained at the desired temperature. A Hettich centrifuge (Model Universal 320R, Germany) was used to accelerate the phase separation process. The $\mathrm{pH}$ values were measured with a Metrohm pH-meter (Model 827) supplied with a glass-combined electrode.

2.2. Reagents and Solutions. All reagents used were of high purity and analytical reagent grade. The water utilized in all studies was double-distilled and deionized. Stock standard solutions of cobalt at a concentration of $1000.0 \mathrm{mg} \mathrm{L}^{-1}$ were prepared by dissolving appropriate amounts of $\mathrm{Co}\left(\mathrm{NO}_{3}\right)_{2}$, $6 \mathrm{H}_{2} \mathrm{O}$ (Merck, Darmstadt, Germany) in deionized doubly distilled water. Before each investigation, a series of metal standard solutions were prepared by diluting this stock solution. The nonionic surfactant Triton X-114 (Sigma-Aldrich, St. Louis, MO, USA) was used without further purification. 4-benzylpiperidinedithiocarbamate potassium salt (K4-BPDC) was prepared according to the procedure described by Andac et al. [23]. Fresh $0.01 \mathrm{~mol} \mathrm{~L}^{-1}$ solution of K-4BPDC was being prepared daily by dissolving an appropriate amount of solid reagent in deionized water.

2.3. Cloud-Point Extraction Procedure. For the cloud point extraction, an analytical solution contained $25 \mathrm{~mL}$ sample
TABLE 1: Optimum conditions for the CPE of cobalt.

\begin{tabular}{lc}
\hline Conditions & Value \\
\hline $\mathrm{pH}$ & 5.0 \\
Concentration of chelating agent $\left(\mathrm{mol} \mathrm{L}^{-1}\right)$ & $2 \times 10^{-4}$ \\
Concentration of surfactant $(\mathrm{w} / \mathrm{v}, \%)$ & 0.1 \\
Equilibrium temperature $\left({ }^{\circ} \mathrm{C}\right)$ & 60 \\
Equilibrium time $(\mathrm{min})$ & 5 \\
Centrifugation rate $(\mathrm{rpm})$ & 5000 \\
Centrifugation time $(\mathrm{min})$ & 5 \\
Diluent & $1.0 \mathrm{~mol} \mathrm{~L}^{-1} \mathrm{HNO}_{3}$ \\
& in ethanol \\
\hline
\end{tabular}

solution or standard solution, $1.0 \mathrm{~mL}$ of $2.5 \%$ (w/v) Triton X$114,0.5 \mathrm{~mL}$ of $0.01 \mathrm{~mol} \mathrm{~L}^{-1} \mathrm{~K}-4-\mathrm{BPDC}$, and $2.5 \mathrm{~mL}$ sodium acetate/acetic acid buffer solution ( $\mathrm{pH} 5.0 ; 0.1 \mathrm{~mol} \mathrm{~L}^{-1}$ ) was transferred to a $50 \mathrm{~mL}$ centrifuge tube and kept in the thermostatic bath maintained at $60^{\circ} \mathrm{C}$ for $10 \mathrm{~min}$. The separation into two phases was accelerated by centrifuging at $5000 \mathrm{rpm}$ for $5 \mathrm{~min}$. The phases were cooled down in an ice bath in order to increase the viscosity of the surfactant-rich phase. The aqueous phase was readily separated by inverting the tubes. To decrease the viscosity of the surfactant-rich phase, $0.3 \mathrm{~mL}$ of $1.0 \mathrm{~mol} \mathrm{~L}^{-1} \mathrm{HNO}_{3}$ in ethanol was added. The resultant solution (volume $0.5 \mathrm{~mL}$ ) was directly introduced into the FAAS by conventional aspiration, and the cobalt content was measured.

\section{Results and Discussion}

To attain higher sensitivity, selectivity and precision for the extraction and determination of cobalt with the CPE method, the effect of main parameters, such as $\mathrm{pH}$, concentration of chelating agent, concentration of surfactant, ionic strength, equilibrium temperature and time, centrifugation conditions, and interfering ions were studied and optimized thoroughly. Triplicate extractions were performed for all experiments, and the selected values are presented in Table 1.

3.1. Effect of $p H$. The $\mathrm{pH}$ was the first critical parameter evaluated for its effect on extraction and determination of cobalt. Separation of metal ions by cloud point method involves the prior formation of a complex with sufficient hydrophobicity to be extracted into the small volume of surfactant-rich phase. Extraction recovery depends on the $\mathrm{pH}$ at which complex formation occurs. In order to find optimum $\mathrm{pH}$, the effect of $\mathrm{pH}$ in the range $1-10$ on the complex formation reaction was investigated, and the results are shown in Figure 1.

As can be seen, the recovery of $\mathrm{Co}$ (II) increases with increasing solution $\mathrm{pH}$ and was effectively recovered in $\mathrm{pH}$ range 4.0-8.0. Competition between protons and metal species could thus explain the weak adsorption in acid medium. On further increase of $\mathrm{pH}$, extraction recovery decreases probably due to the formation of hydroxide of cobalt. Therefore, the further works were performed at $\mathrm{pH}$ 5.0. In order to control the $\mathrm{pH}$ during the analytical 


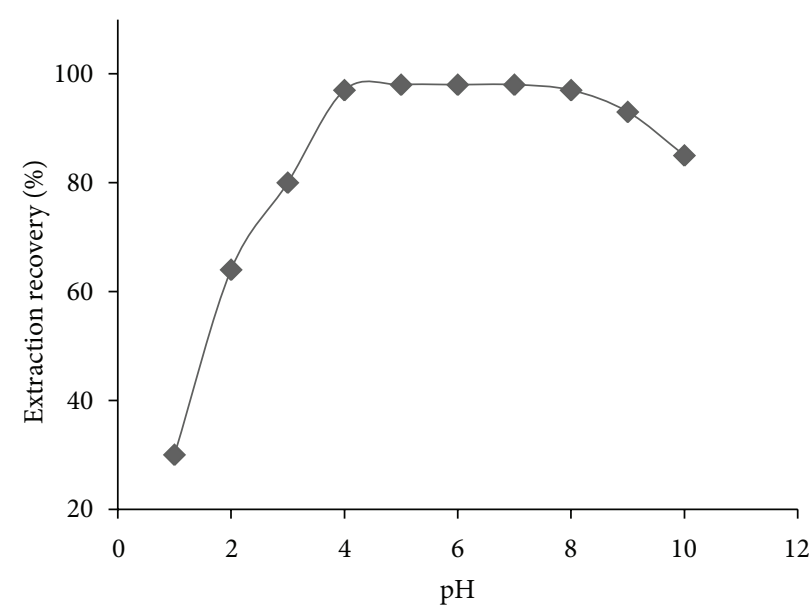

Figure 1: Effect of $\mathrm{pH}$ on cobalt extraction recovery. Utilized conditions: sample: $25 \mathrm{~mL}, 100 \mu \mathrm{g} \mathrm{L}^{-1}$; chelating agent: $2.0 \times 10^{-4} \mathrm{~mol} \mathrm{~L}-1$ of K-4-BPDC; surfactant: $0.1 \%(\mathrm{w} / \mathrm{v})$ of Triton X-114.

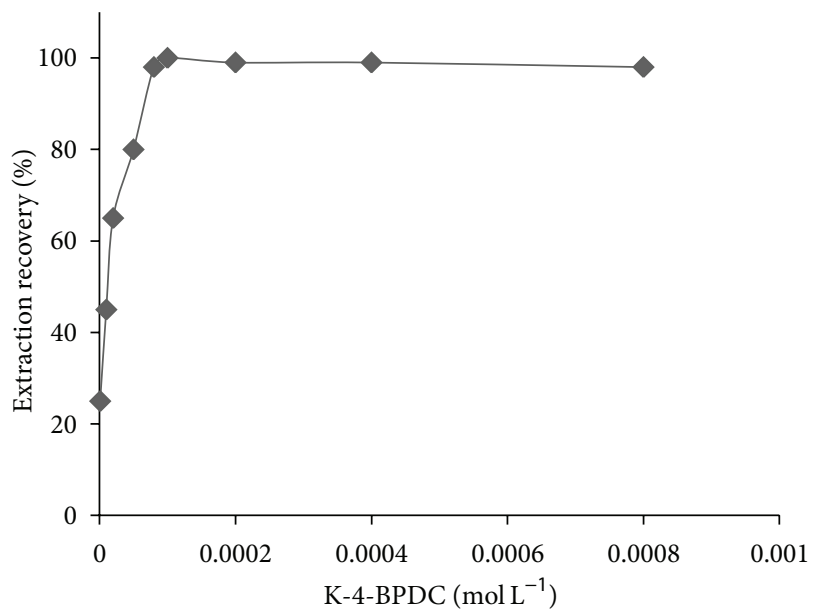

Figure 2: Effect of K-4-BPDC concentration on cobalt extraction recovery. Utilized conditions: sample: $25 \mathrm{~mL}, 100 \mu \mathrm{g} \mathrm{L}$; $\mathrm{pH}=5.0$; surfactant: $0.1 \%(\mathrm{w} / \mathrm{v})$ of Triton X-114.

procedure, it was adjusted to 5.0 with a buffer solution of sodium acetate/acetic acid.

3.2. Effect of Chelating Agent Concentration. The concentration of the chelating agent may be sufficient for the quantitative complexing of metal ions. The lower concentration of $\mathrm{K}-4$-BPDC led to a reduction in the analytical response due to incomplete complexing of the metal and consequently, a lower extraction yield. The extraction recovery as a function of the K-4-BPDC concentration is shown in Figure 2. For this study, $25 \mathrm{~mL}$ of a solution containing $100 \mu \mathrm{g} \mathrm{L}^{-1}$ cobalt and $0.1 \%(\mathrm{w} / \mathrm{v})$ Triton X-114 with various amounts of K-4-BPDC was subjected to the cloud point preconcentration process. As can be seen, CPE efficiency increased rapidly as the concentration of K-4-BPDC increased from $1 \times 10^{-6} \mathrm{~mol} \mathrm{~L}^{-1}$ to $1 \times 10^{-4} \mathrm{~mol} \mathrm{~L}^{-1}$, then remained almost constant upon further increase in the K-4-BPDC concentration up to
$8 \times 10^{-4} \mathrm{~mol} \mathrm{~L}^{-1}$. Therefore, K-4-BPDC concentration of $2 \times$ $10^{-4} \mathrm{~mol} \mathrm{~L}^{-1}$ was chosen for subsequent experiments.

3.3. Effect of Triton $X-114$ Concentration. The type and concentration of surfactant, that is used in the CPE, are critical factors. The amount of surfactant did not only affect the extraction efficiency, but also the volume of surfactant-rich phase. A successful cloud point extraction should maximize the extraction efficiency by minimizing the phase volume ratio $\left(V_{\text {org }} / V_{\text {aqueous }}\right)$, thus improving its concentration factor [30].

Triton X-114 was chosen for the formation of the surfactant-rich phase due to its low cloud-point temperature and high density of the surfactant-rich phase, which facilitates phase separation by centrifugation. Thus, amount of Triton $\mathrm{X}-114$ was investigated between 0.02 and $0.25 \%$ for extraction performance. The results are given in Figure 3. Quantitative extraction is observed when the Triton X-114 concentration 


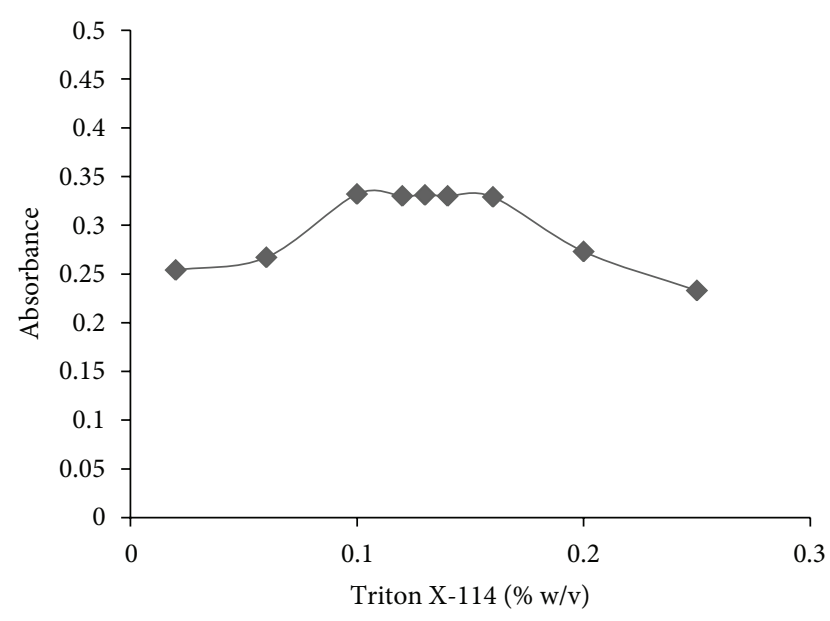

FIGURE 3: Effect of Triton X-114 concentration on absorbance signal. Utilized conditions: sample: $25 \mathrm{~mL}, 100 \mu \mathrm{g} \mathrm{L}^{-1} ; \mathrm{pH}=5.0$; chelating agent: $2.0 \times 10^{-4} \mathrm{~mol} \mathrm{~L}^{-1}$ of K-4-BPDC.

TABLE 2: Effect of foreign ions on the recovery of cobalt $\left(100 \mu \mathrm{g} \mathrm{L}^{-1}\right)$.

\begin{tabular}{lcc}
\hline Ion & Ion/Co(II) ratio & Recovery $(\%)$ \\
\hline $\mathrm{NO}_{3}{ }^{-}$ & 1000 & 99.8 \\
$\mathrm{ClO}_{4}{ }^{-}$ & 1000 & 100.1 \\
$\mathrm{~K}^{+}$ & 1000 & 99.8 \\
$\mathrm{Li}^{+}$ & 1000 & 99.6 \\
$\mathrm{Cl}^{-}$ & 1000 & 99.4 \\
$\mathrm{SO}_{4}{ }^{2-}$ & 1000 & 99.7 \\
$\mathrm{I}^{-}$ & 1000 & 99.6 \\
$\mathrm{~F}^{-}$ & 1000 & 99.7 \\
$\mathrm{PO}_{4}{ }^{3-}$ & 500 & 99.4 \\
$\mathrm{Ca}^{2+}$ & 500 & 99.8 \\
$\mathrm{Mg}^{2+}$ & 500 & 99.8 \\
$\mathrm{Cu}^{2+}$ & 100 & 100.2 \\
$\mathrm{Fe}^{2+}$ & 100 & 101.2 \\
$\mathrm{Fe}^{3+}$ & 100 & 101.1 \\
$\mathrm{Mn}^{2+}$ & 50 & 99.1 \\
$\mathrm{Cr}^{3+}$ & 50 & 101.3 \\
$\mathrm{Al}^{3+}$ & 50 & 100.6 \\
$\mathrm{Bi}^{3+}$ & 30 & 102.1 \\
$\mathrm{Cd}^{2+}$ & 30 & 101.3 \\
$\mathrm{Zn}^{2+}$ & 30 & 102.2 \\
$\mathrm{Ag}^{+}$ & 5 & 97.9 \\
$\mathrm{Hg}^{2+}$ & 57.8 \\
\hline
\end{tabular}

is higher than $0.10 \%(\mathrm{w} / \mathrm{v})$. At lower concentrations, the absorbance is low probably because of the inadequacy of the assemblies to entrap the hydrophobic complex quantitatively. With increase of Triton X-114 concentration above $0.16 \%$ $(\mathrm{w} / \mathrm{v})$, the signals decrease because of the increment in the volumes and the viscosity of the surfactant phase, leading to poor sensitivity. Since, a concentration of $0.1 \%(\mathrm{w} / \mathrm{v})$ of
TABLE 3: Analytical characteristics of proposed method.

\begin{tabular}{lc}
\hline Parameter & Analytical feature \\
\hline Linear range, $\mu \mathrm{g} \mathrm{L}^{-1}$ & $2-150$ \\
Limit of detection, $\mu \mathrm{g} \mathrm{L}^{-1} \quad(n=10)$ & 0.5 \\
$\mathrm{RSD}(\%)\left(n=10 ; C=100 \mu \mathrm{g} \mathrm{L}^{-1}\right)$ & 3.2 \\
Preconcentration factor & 50 \\
Enhancement factor & 67 \\
\hline
\end{tabular}

Triton X-114 was chosen as optimum concentration for subsequent experiments.

3.4. Effect of Equilibration Temperature and Time. It is desirable to have the shortest incubation time and the lowest possible equilibration temperature, which compromise completion of the reaction and efficient separation of the phases. The effect of the equilibration temperature and time was studied with a range of $25-80^{\circ} \mathrm{C}$ and 5-30 min, respectively. It was found that an equilibration temperature of $60^{\circ} \mathrm{C}$ and a time of $10 \mathrm{~min}$ were adequate to achieve quantitative extraction.

3.5. Effect of Viscosity. In order to facilitate the sample introduction in FAAS nebulizer, it was necessary to decrease the surfactant-rich phase viscosity. Different solvents such as acetone, ethanol, methanol, and acidic solutions of ethanol and methanol were tried in order to select the one producing the optimal results regarding sensitivity. The best result was obtained for acidic solution of ethanol. A volume of $0.3 \mathrm{~mL}$ of ethanol solution containing $1 \mathrm{~mol} \mathrm{~L}^{-1}$ nitric acid was added to the surfactant-rich phase after separation. This amount of ethanol was chosen to ensure a sufficient volume of sample for conventional aspiration. For smaller volumes, the reproducibility of the signals was very poor, whereas for higher volumes, there was a decrease in the signal due to dilution.

3.6. Effect of Ionic Strength. For investigating the influence of ionic strength on performance of CPE, various experiments were performed by adding different amounts of $\mathrm{NaCl}$ $\left(0-1.0 \mathrm{~mol} \mathrm{~L}^{-1}\right)$. Other experimental conditions were kept constant. The results showed that ionic strength has no significant effect on the extraction recovery.

3.7. Centrifuging Rate and Time. To achieve a good separation result, the effect of centrifugation rate and time on the extraction recovery of cobalt were studied. The effect of centrifugation rate was investigated in the range of 1000-6000 rpm. It showed that over $4000 \mathrm{rpm}$, surfactant phase completely settled, so the rate of $5000 \mathrm{rpm}$ was selected as the optimum point.

At the optimum rate, recovery was examined as a function of centrifugation time. Over $4 \mathrm{~min}$, absorbance was constant indicating complete transfer of surfactant phase to the bottom of centrifuge tube. So, the optimum centrifugation time was chosen as $5 \mathrm{~min}$. 
TABLE 4: Determination of Co(II) in tap, mineral, river, and sea water samples and relative recoveries of spiked samples.

\begin{tabular}{|c|c|c|c|c|}
\hline Sample & $\begin{array}{c}\mathrm{Co}(\mathrm{II}) \pm \mathrm{S} . \mathrm{D} .^{a} \\
\left(\mu \mathrm{g} \mathrm{L}^{-1}\right)\end{array}$ & $\begin{array}{l}\text { Added Co(II) } \\
\left(\mu \mathrm{gL}^{-1}\right)\end{array}$ & $\begin{array}{l}\text { Found } \mathrm{Co}(\mathrm{II}) \pm \text { S.D. }^{a} \\
\left(\mu \mathrm{g} \mathrm{L}^{-1}\right)\end{array}$ & Recovery (\%) \\
\hline & & - & - & - \\
\hline \multirow[t]{3}{*}{ Tap water ${ }^{b}$} & n.d. ${ }^{f}$ & 50.0 & $51.6 \pm 1.8$ & 103.2 \\
\hline & & 100.0 & $102.1 \pm 3.9$ & 102.1 \\
\hline & & - & - & - \\
\hline \multirow[t]{3}{*}{ Mineral water $^{c}$} & n.d. & 50.0 & $49.0 \pm 1.7$ & 98.0 \\
\hline & & 100.0 & $98.7 \pm 3.2$ & 98.7 \\
\hline & & - & - & - \\
\hline \multirow[t]{3}{*}{ River water $^{d}$} & $8.5 \pm 0.3$ & 50.0 & $56.2 \pm 1.9$ & 95.4 \\
\hline & & 100.0 & $105.6 \pm 3.7$ & 97.1 \\
\hline & & - & - & - \\
\hline \multirow[t]{2}{*}{ Sea water ${ }^{e}$} & $9.4 \pm 0.5$ & 50.0 & $56.5 \pm 1.6$ & 94.2 \\
\hline & & 100.0 & $106.2 \pm 3.5$ & 96.8 \\
\hline
\end{tabular}

Standard deviation $(n=5)$.

${ }^{b}$ Behshahr drinking water system, Iran.

${ }^{c}$ Damavand mineral water, Iran.

${ }^{d}$ Tajan river water, north of Iran.

${ }^{e}$ Caspian sea water, Iran.

${ }^{f}$ Not detected.

TABLE 5: Comparison of the presented method with other methods for determination of cobalt.

\begin{tabular}{|c|c|c|c|c|c|}
\hline Method & $\operatorname{LOD}^{a}\left(\mu \mathrm{g} \mathrm{L}^{-1}\right)$ & $\mathrm{RSD}^{b}(\%)$ & Sample volume (mL) & $\mathrm{PF}^{c}$ & Reference \\
\hline CPE-spectrophotometry & 7.5 & 2.7 & 10 & 10 & {$[24]$} \\
\hline CPE-FAAS & 1.0 & 3.6 & 50 & 25 & {$[25]$} \\
\hline SPE-FAAS & 3.4 & 1.3 & 1300 & 260 & {$[26]$} \\
\hline SPE-FAAS & 12.3 & 1.3 & 1000 & 200 & {$[27]$} \\
\hline SPE-FAAS & 3.9 & 2.0 & 250 & 25 & [28] \\
\hline DLLME-FAAS & 0.9 & 5.8 & 5 & 16 & {$[29]$} \\
\hline CPE-FAAS & 0.5 & 3.2 & 25 & 50 & This work \\
\hline
\end{tabular}

Limit of detection.

${ }^{b}$ Relative standard deviation.

${ }^{c}$ Preconcentration factor.

3.8. Interferences. The effect of foreign ions on the determination of cobalt by the proposed method was investigated by measuring the absorbance of the solutions containing $100 \mu \mathrm{g} \mathrm{L}^{-1}$ of cobalt ion in the presence of various amounts of other ions. The tolerance limit was defined as the concentration of added ion that caused less than $\pm 5 \%$ relative error in the determination of cobalt. The maximum tolerances of the investigated cations and anions are given in Table 2. According to the results, cobalt recovery was nearly quantitative in the presence of other ions.

3.9. Analytical Features. The calibration graph was linear in the range of $2-150 \mu \mathrm{g} \mathrm{L}^{-1}$ under the optimum conditions of general procedure. The correlation coefficient of the calibration curve equation was 0.997 , which indicates that a good linear regression was established between the absorbances and the concentrations. The preconcentration factor for $\mathrm{Co}(\mathrm{II})$ calculated by dividing the aqueous phase volume into the final volume of diluted phase was 50, while the enhancement factor as the ratio of slope of calibration curve of the analytes after preconcentration to that prior preconcentration was 67. The limit of detection (LOD) is defined as the concentration equivalent to three times the standard deviation of 10 measurements of the blank and is the lowest analyte concentration that produces a response detectable above the noise level of the system. Table 3 gives the analytical features of the method.

3.10. Determination of Cobalt in Real Water Samples. The proposed method was applied in the determination of cobalt in tap water, mineral water, river water, and seawater samples. The results are given in Table 4 . Recovery studies were also carried out after it was spiked to samples known concentrations of cobalt at levels of 50 and $100 \mu \mathrm{g} \mathrm{L}^{-1}$. The recovery values calculated for the added standards ranged from 94 to $103 \%$, thus confirming the accuracy of the procedure and its 
independence from the matrix effects. These results confirm the validity of the proposed preconcentration method.

3.11. Comparison of Proposed Method with Other Methods. A comparison of the represented method with some other reported preconcentration methods for cobalt determination in water samples is given in Table 5. Apparently, presented method has low LOD, high-enrichment factor, good RSD, and these characteristics are comparable or even better than most of the other methods in Table 5.

\section{Conclusion}

The reagent 4-benzylpiperidinedithiocarbamate potassium salt (K-4-BPDC) was successfully employed in a CPE procedure for determination of cobalt in natural water samples by FAAS. This study allowed the development of a rapid, easy to use, safe, environmental friendly, and inexpensive methodology for the preconcentration and separation of trace amounts of cobalt. The method significantly improved the performance of the FAAS detection for cobalt. The proposed preconcentration method allows cobalt determination in natural water samples at $\mu \mathrm{g} \mathrm{L}^{-1}$ levels.

\section{Acknowledgment}

The support of this paper by The Research Council of Payame Noor University through Grant is gratefully acknowledged.

\section{References}

[1] B. C. Mondal, D. Das, and A. K. Das, "Preconcentration and separation of copper, zinc and cadmium by the use of 6mercapto purinylazo resin and their application in microwave digested certified biological samples followed by AAS determination of the metal ions," Journal of Trace Elements in Medicine and Biology, vol. 16, no. 3, pp. 145-148, 2002.

[2] A. I. Yuzefovsky, R. F. Lonardo, M. Wang, and R. G. Michel, "Determination of ultra-trace amounts of cobalt in ocean water by laser-excited atomic fluorescence spectrometry in a graphite electrothermal atomizer with semi on-line flow injection preconcentration," Journal of Analytical Atomic Spectrometry, vol. 9, pp. 1195-1202, 1994.

[3] H. L. Bohn, B. L. McNeal, and G. A. O’Connor, Soil Chemistry, John Wiley \& Sons, Chichester, UK, 2nd edition, 1985.

[4] P. L. Malvankar and V. M. Shinde, "Ion-pair extraction and determination of copper(II) and zinc(II) in environmental and pharmaceutical samples," Analyst, vol. 116, no. 10, pp. 1081-1084, 1991.

[5] A. Akdogan, M. Deniz, S. Cebecioglu, A. Sen, and H. Deligoz, "Liquid-liquid extraction of transition metal cations by nine new azo derivatives calix[n]arene," Separation Science and Technology, vol. 37, no. 4, pp. 973-980, 2002.

[6] S. Y. Bae, X. Zeng, and G. M. Murray, "Photometric method for the determination of $\mathrm{Pb}^{2+}$ followingseparation and preconcentration using a templated ion-exchange resin," Journal of Analytical Atomic Spectrometry, vol. 13, pp. 1177-1180, 1998.
[7] N. Prakashi, G. Csanady, R. A. Michaelis, and G. Knapp, "Automatic off/on-line preconcentration for ICP-OES: powerful instrumentation for water analysis," Microchimica Acta, vol. 99, no. 3-6, pp. 257-265, 1989.

[8] M. Vircaus, V. Rone, A. Palne, and D. Vircava, "Coprecipitation behaviour of 5,8-polyquinolyl polydisulphide for trace element preconcentration from aqueous solution," Analytica Chimica Acta, vol. 299, no. 2, pp. 291-298, 1994.

[9] L. Elci, U. Sahin, and S. Oztas, "Determination of trace amounts of some metals in samples with high salt content by atomic absorption spectrometry after cobalt-diethyldithiocarbamate coprecipitation," Talanta, vol. 44, no. 6, pp. 1017-1023, 1997.

[10] S. Gucer and M. Yaman, "Determination of vanadium in vegetable matter by flame atomic absorption spectrometry," Jour-nal of Analytical Atomic Spectrometry, vol. 7, pp. 179-182, 1992.

[11] K. Santhy and P. Selvapathy, "Removal of heavy metals from wastewater by adsorption on coir pith activated carbon," Separation Science and Technology, vol. 39, no. 14, pp. 3331-3351, 2004.

[12] A. Ramesh, K. R. Mohan, and K. Seshaiah, "Preconcentration of trace metals on amberlite XAD-4 resin coated with dithiocarbamates and determination by inductively coupled plasma-atomic emission spectrometry in saline matrices," Talanta, vol. 57, no. 2, pp. 243-252, 2002.

[13] M. Soylak, U. Sahin, and L. Elci, "Spectrophotometric determination of molybdenum in steel samples utilizing selective sorbent extraction on amberlite XAD-8 resin," Analytica Chimica Acta, vol. 322, no. 1-2, pp. 111-115, 1996.

[14] R. M. C. Suttun, S. J. Hill, and P. Jones, "Comparison of the chelating ion exchange properties of dye coated cellulose and polystyrene substrates for the separation and determination of trace metals from aqueous media," Journal of Chromatography A, vol. 739, no. 1-2, pp. 81-86, 1996.

[15] B. Mohammad, A. M. Ure, and D. Littlejohn, "On-line preconcentration of aluminium with immobilized 8-hydroxyquinoline for determination by atomic absorption spectrometry," Journal of Analytical Atomic Spectrometry, vol. 7, no. 4, pp. 695-699, 1992.

[16] W. L. Hinze and E. Pramauro, "A critical review of surfactantmediated phase separations (cloud-point extractions): theory and applications," Critical Reviews in Analytical Chemistry, vol. 24, no. 2, pp. 133-177, 1993.

[17] R. Carabias-Martınez, E. Rodriguez-Gonzalo, B. MorenoCordero, J. L. Perez-Pavon, C. Garcia-Pinto, and E. Fernandez Laespada, "Surfactant cloud point extraction and preconcentration of organic compounds prior to chromatography and capillary electrophoresis," Journal of Chromatography A, vol. 902, no. 1, pp. 251-265, 2000.

[18] E. K. Paleogos, D. L. Giokas, and M. I. Karayannis, "Micellemediated separation and cloud-point extraction," Trends in Analytical Chemistry, vol. 24, no. 5, pp. 426-436, 2005.

[19] C. D. Stalikas, "Micelle-mediated extraction as a tool for separation and preconcentration in metal analysis," Trends in Analytical Chemistry, vol. 21, no. 5, pp. 343-355, 2002.

[20] M. Soylak, L. Elci, I. Narin, and M. Dogan, "Application of solid phase extraction for the preconcentration and separation of trace amounts of cobalt from urine," Trace Elements and Electrolytes, vol. 18, pp. 26-29, 2001.

[21] M. Soylak, L. Elci, I. Narin, and M. Dogan, "Flame atomic absorption spectrometric determination of cadmium, cobalt, copper, lead and nickel in chemical grade potassium salts after 
an enrichment and separation procedure," Journal of Trace and Microprobe Techniques, vol. 17, pp. 149-156, 1999.

[22] M. Soylak, S. Saracoglu, U. Divrikli, and L. Elci, "Membrane filtration-atomic absorption spectrometry combination for copper, cobalt, cadmium, lead and chromium in environmental samples," Environmental Monitoring and Assessment, vol. 127, no. 1-3, pp. 169-176, 2007.

[23] M. Andac, A. Asan, I. Isildak, and H. Cesur, "Flow-injection spectrophotometric determination of cobalt(II) at low $\mu \mathrm{g}$ $1^{-1}$ levels with 4-benzylpiperidinedithiocarbamate," Analytica Chimica Acta, vol. 434, no. 1, pp. 143-147, 2001.

[24] A. Safavi, H. Abdollahi, M. R. Hormozi Nezhad, and R. Kamali, "Cloud point extraction, preconcentration and simultaneous spectrophotometric determination of nickel and cobalt in water samples," Spectrochimica Acta A, vol. 60, no. 12, pp. 2897-2901, 2004.

[25] D. Citak and M. Tuzen, "A novel preconcentration procedure using cloud point extraction for determination of lead, cobalt and copper in water and food samples using flame atomic absorption spectrometry," Food and Chemical Toxicology, vol. 48, no. 5, pp. 1399-1404, 2010.

[26] M. Ghaedi, F. Ahmadi, and A. Shokrollahi, "Simultaneous preconcentration and determination of copper, nickel, cobalt and lead ions content by flame atomic absorption spectrometry," Journal of Hazardous Materials, vol. 142, no. 1-2, pp. 272-278, 2007.

[27] D. Afzali and S. Z. Mohammadi, "Determination trace amounts of copper, nickel, cobalt and manganese ions in water samples after simultaneous separation and preconcentration," Environmental Chemistry Letters, vol. 9, no. 1, pp. 115-119, 2011.

[28] S. Baytak and A. R. Turker, "Determination of iron(III), cobalt(II) and chromium(III) in various water samples by flame atomic absorption spectrometry after preconcentration by means of Saccharomyces Carlsbergensis immobilized on amberlite XAD-4," Microchimica Acta, vol. 149, no. 1-2, pp. 109-116, 2005.

[29] P. X. Baliza, L. S. G. Teixeira, and V. A. Lemos, "A procedure for determination of cobalt in water samples after dispersive liquidliquid microextraction," Microchemical Journal, vol. 93, no. 2, pp. 220-224, 2009.

[30] T. G. Kazi, S. Khan, J. A. Baig, N. F. Kolachi, H. I. Afridi, and A. Q. Shah, "Determination of trace quantity of aluminium in dialysate concentrates using solid phase and cloud point extraction methods," Analytical Methods, vol. 2, no. 5, pp. 558-563, 2010. 

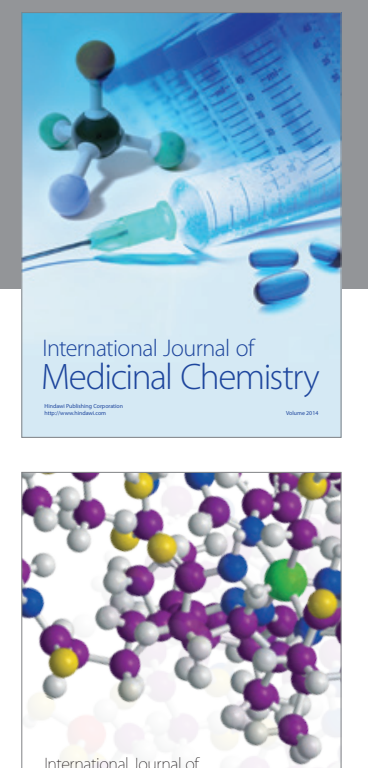

\section{Carbohydrate} Chemistry

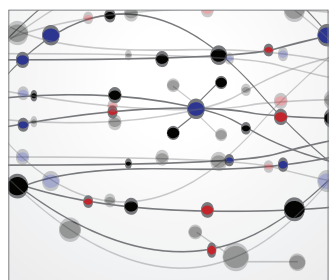

The Scientific World Journal
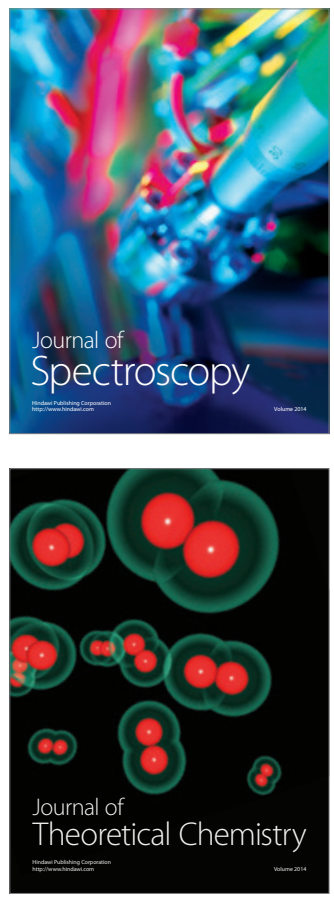
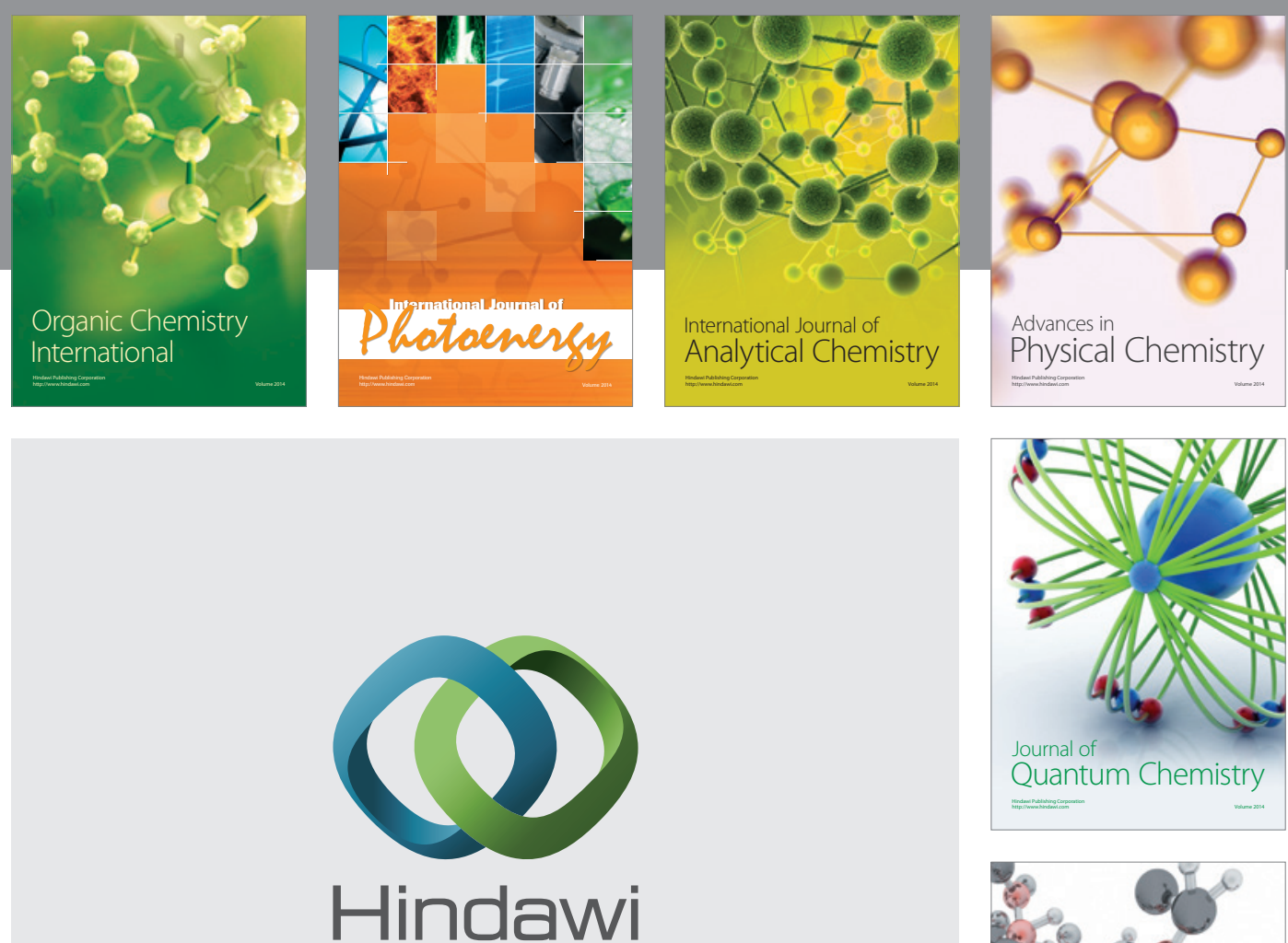

Submit your manuscripts at

http://www.hindawi.com

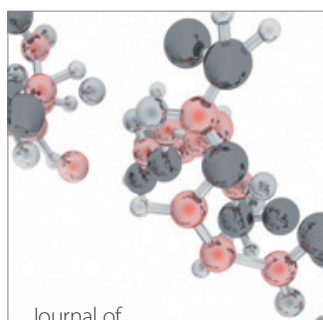

Analytical Methods

in Chemistry

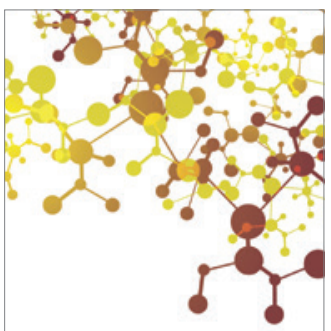

Journal of

Applied Chemistry

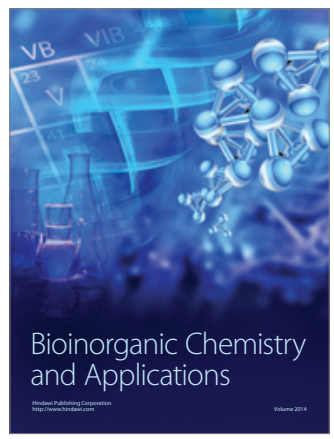

Inorganic Chemistry
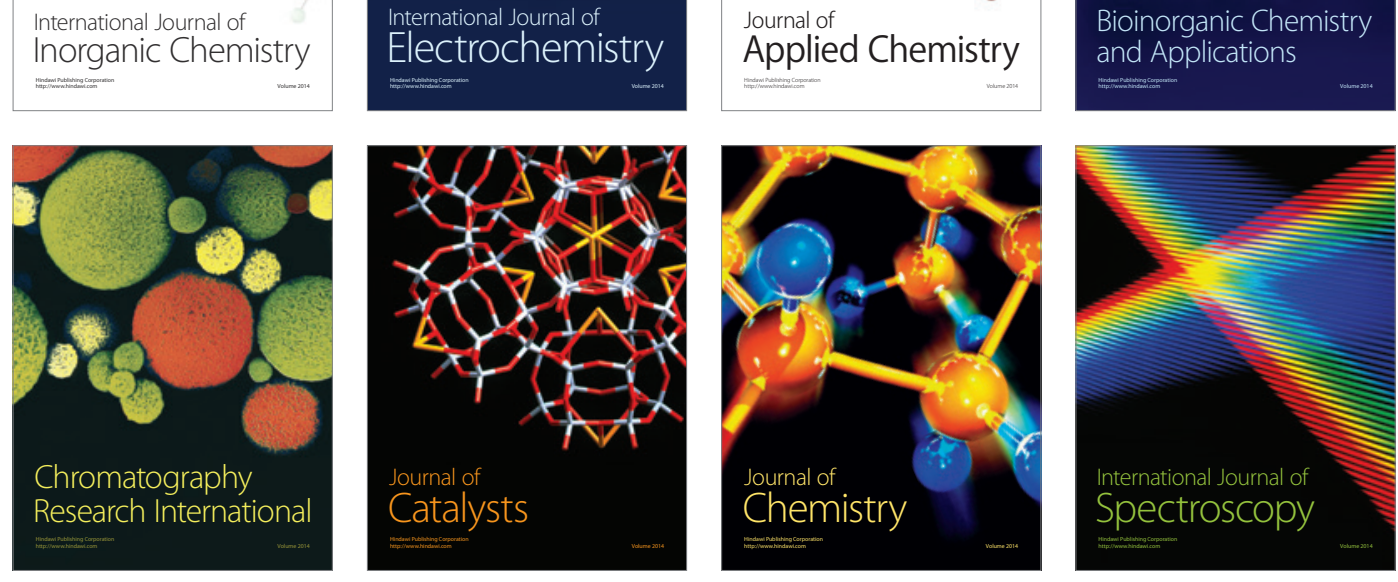